\title{
Estela e o projeto fazendo arte com a Matemática
}

\section{Katia Regina Ashton Nunes}

Associação Educacional Miraflores - Niterói-RJ

katiaanunes@hotmail.com

\section{Resumo}

Este artigo tem por objetivo apresentar um breve relato da trajetória profissional da educadora Estela Kaufman Fainguelernt que dedicou grande parte de sua vida à pesquisa e à formação inicial e continuada de gerações de professores de Matemática, e que durante anos encantou a todos com sua alegria, dedicação, competência, paixão, e grande vitalidade. O texto ainda discorre sobre o Projeto Matemática e Arte que desenvolveu em parceria com a professora Katia Regina Ashton Nunes e descreve, de forma reduzida, um dos muitos trabalhos que realizaram em conjunto com artistas plásticos de destaque mundial.

Palavras-chave: Estela Fainguelernt. Educação Matemática. Geometria. Arte.

\section{Estela and the creating arts with Mathematics project}

This article aims to introduce a short report on the career of the educator Estela Kaufman Fainguelernt, who dedicated most of her life to research and the continuous development of many generations of Mathematics teachers and that, through many years, charmed all those who knew her with her joy, dedication, professionalism, passion and great vitality. This text also covers the Mathematics and Arts project which she developed together with Katia Regina Ashton Nunes and describes in reduced form one of the many works they created hand in hand with noticeable characters in the world's art scene.

Keywords: Estela Fainguelernt. Mathematic Education. Geometry. Art. 


\section{Estela, grande mestra e amiga eterna}

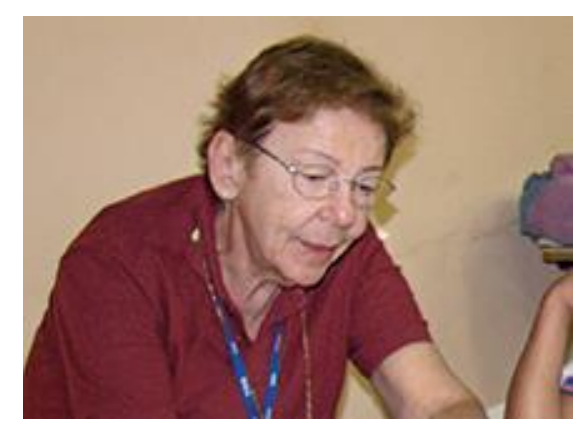

Quando se fala em Educação Matemática e em especial no ensino de geometria, não se pode deixar de citar a doutora Estela Kaufman Fainguelernt, educadora das mais apaixonadas e atuantes, que dedicou grande parte de sua vida à pesquisa e à formação inicial e continuada de gerações de professores de Matemática. Ela nos faz lembrar a dinâmica e revolucionária "professora maluquinha", personagem criada por Ziraldo Alves Pinto, que tinha estrelas no lugar do olhar, e que fez grande diferença na vida de seus alunos. Estela, cujo nome se originou da palavra em latim stella, que significa "estrela", conquistava a todos com sua alegria, dedicação, competência, paixão, e grande vitalidade.

Ela nasceu em 1933, no Rio de Janeiro, onde estudou e obteve sua formação como bacharel e licenciada em Matemática em 1955, pela Faculdade Nacional de Filosofia, atualmente Universidade Federal do Rio de Janeiro (UFRJ). Fez mestrado em Ciência de Engenharia de Sistemas e Computação na COPPE, da UFRJ, em 1981, e em 1996, doutorado em Engenharia de Sistemas, Tecnologia e Sociedade, também pela COPPE.

Pioneira da Educação Matemática em nosso país, Estela deixa sua marca e um legado para quem se dedica à Educação Matemática. Ela participou dos importantes movimentos, eventos e congressos da área e ministrou inúmeros cursos de formação para professores. Participou, em 1976, da criação do GEPEM (Grupo de Estudos e Pesquisas em Educação Matemática) juntamente com Maria Laura Mouzinho Leite Lopes, Moema Sá Carvalho, Anna Averbuch, e Franca Cohen Gottlieb, dentre outros. Foi uma das sócias fundadoras da Sociedade Brasileira de Educação Matemática (SBEM), criada em 1988. Em 1989 ajudou a criar o primeiro Mestrado em Educação Matemática no Estado do Rio de Janeiro, o da Universidade Santa Úrsula (USU), que foi fundamental para a consolidação dessa área no estado e para a formação de grandes professores e pesquisadores que hoje compõem o cenário brasileiro.

Foi professora, coordenadora e diretora do Curso de Matemática da Universidade Estácio de Sá, Rio de Janeiro. Lecionou na Licenciatura em Matemática do Centro Educacional Serra dos Órgãos (UNIFESO), em Teresópolis, Rio de Janeiro. E em 2002, começou na Universidade 
Severino Sombra, em Vassouras - Rio de Janeiro. Foi professora da Licenciatura em Matemática e da Pós-graduação em Educação Matemática, e ainda ajudou a criar o Mestrado Profissional em Educação Matemática, em 2008. Nesta instituição recebeu, em 2012, uma importante homenagem com a publicação da dissertação Uma História de Paixão: Estela Kaufman Fainguelernt e o Ensino da Geometria, de Marcelo Ferreira Salvador que foi orientado pela $\operatorname{Dr}^{\mathrm{a}}$ Lucia Villela.

Estela também publicou diversos artigos e livros. Dentre eles a inovadora Coleção “Trabalhando com a Geometria”, publicada pela editora Ática, em 1989.

Todos que, como eu, tiveram o prazer e a honra de conhecê-la e participar de seus cursos e palestras logo perceberam a sua enorme paixão pelo magistério, pela educação e, em especial, pelo ensino de geometria.

Meu encontro com Estela se deu no início da década de 1980, quando ainda iniciava a minha carreira como professora e pesquisadora. Durante os congressos e eventos de educação matemática de que participávamos nasceu de minha parte uma grande admiração e encantamento por sua empolgação e por seu trabalho.

Em 2000 iniciei o Mestrado em Educação Matemática na Universidade Santa Úrsula (USU), e assim nosso contato passou a ser mais constante e minha admiração por Estela só aumentou. Naquele ano tive o privilégio de tê-la como professora, e desde então nutri a vontade de tê-la como orientadora, especialmente após adquirir seu livro Educação Matemática: Representação e Construção em Geometria, publicado em 1999 pela editora Artmed, que descreve sua tese de doutorado e no qual ela relata um trabalho realizado com as obras do artista holandês Maurits Cornelis Escher. Como eu trabalhava com Matemática e Arte desde 1995, Estela tornou-se assim a orientadora ideal.

Em 2002 defendi a dissertação intitulada Um olhar matemático no mundo das artes - a arte do século XX como veículo de aprendizagem em geometria, sob sua orientação e da professora Franca Cohen Gottlieb. A dissertação gerou, em 2005, nossa primeira parceria no livro Fazendo Arte com a Matemática, que ganhou uma nova edição, totalmente reformulada, em 2015. Publicamos ainda mais três livros: Tecendo Matemática com Arte, Descobrindo Matemática na Arte, Matemática - Práticas Pedagógicas para o Ensino Médio, todos eles publicados pelo Grupo A / Artmed/Penso.

Em todos esses anos de convívio aprendi muito com a educadora Estela Kaufman Fainguelernt, minha mestra inspiradora e de toda uma legião de educadores matemáticos. Todavia posso garantir que o meu maior aprendizado foi com a pessoa Estela, amiga eterna.

A partir de agora farei um breve relato do nosso trabalho com Matemática e Arte, apresentando um dos muitos projetos que desenvolvemos ao longo desses anos de parceria. 


\section{O projeto matemática e arte}

O matemático, tal como o pintor ou o poeta, é um criador de padrões. Um pintor faz padrões com formas e cores, um poeta com palavras e o matemático com ideias. Todos os padrões devem ser belos. As ideias, tal como as cores, as palavras ou os sons, devem ajustar-se de forma perfeita e harmoniosa (G. H. Hardy).

Ao escolhermos pesquisar o tema Matemática e Arte, nossa intenção foi trabalhar com a Matemática de forma mais significativa e integrada, transformando um espaço onde o aluno costumava ser mero expectador do olhar e saber dos outros em um ambiente onde ele pudesse participar ativamente do processo de construção de seu conhecimento; um espaço onde a intuição, a sensibilidade, a imaginação, a criatividade e a criação se fizessem presentes. E a Arte se mostrou uma área bastante propícia à concretização de nossos objetivos.

A arte não é apenas básica, mas fundamental na educação de um país que se desenvolve [...] Não é possível o desenvolvimento de uma cultura sem o desenvolvimento das suas formas artísticas. Não é possível uma educação intelectual, formal ou informal, sem a arte, porque é impossível o desenvolvimento integral da inteligência sem o desenvolvimento do pensamento divergente, do pensamento visual e do conhecimento representacional que caracterizam a arte. Se pretendemos uma educação não apenas intelectual, mas principalmente humanizadora, a necessidade da arte é ainda mais crucial para desenvolver a percepção e a imaginação, para captar a realidade circundante e desenvolver a capacidade criadora necessárias à modificação desta realidade. (BARBOSA, 2005, p. 5)

Além disso, a vivência em Arte favorece o desenvolvimento da criatividade e fornece ferramentas de sensibilidade e de compreensão para lidar com a vida como um todo.

O aluno que conhece arte pode estabelecer relações mais amplas quando estuda um determinado período histórico. Um aluno que exercita continuamente sua imaginação estará mais habilitado a construir um texto, a desenvolver estratégias pessoais para desenvolver um problema matemático. (PCN Arte, 1998, p. 5)

A princípio, a proposta de integrar Matemática e Arte pode causar estranheza. O que haveria de comum entre essas duas disciplinas, uma tão relacionada com o racional, e outra tão evidentemente ligada ao sensível, ao imaginativo?

A ideia de que o pensamento matemático se reduz a seus aspectos lógico dedutivos - uma ideia muito difundida, mesmo entre professores de matemática- é incompleta e exclui o que há de mais rico nos processos de invenção e descoberta nesse domínio do conhecimento. A verdade é que o pensamento matemático vai muito além do raciocínio lógico. Em seus aspectos mais criativos, a matemática está ligada muito mais à intuição e à imaginação do que ao raciocínio lógico dedutivo. (ÁVILA, 1995, p. 2) 
Durante nossa investigação ficou claro que essas duas áreas do conhecimento, a Matemática e a Arte sempre caminharam juntas, aliando razão e sensibilidade. Podemos observar a influência mútua de uma sobre a outra desde os primeiros registros históricos que temos de ambas. Muitos artistas utilizaram elementos matemáticos na confecção de suas obras.

Uma das mais notáveis influências da Matemática sobre a Arte ocorreu no Renascimento. Até então as gravuras e pinturas eram "bidimensionais". A partir dessa época, os artistas dominaram a técnica de projetar em uma tela plana figuras e ambientes a três dimensões. Surgia a noção de perspectiva. Leonardo da Vinci, o nome mais conhecido do Renascimento, dizia: "Que ninguém que não seja matemático leia minhas obras."

Os exemplos do encontro entre Matemática e Arte podem ser multiplicados enormemente. O francês Paul Cézanne simplificava as figuras que via, até transformá-las em sólidas formas geométricas, como círculos, cubos, cilindros, cones. Impossível não citar o espanhol Pablo Picasso e o francês Georges Braque que criaram o Cubismo, movimento artístico cuja proposta centrava-se na liberdade que o artista deveria ter para decompor e recompor a realidade a partir de elementos geométricos. Este movimento rompia com as leis da perspectiva, mostrando todos os lados e partes do objeto em questão em um único plano.

O poeta italiano Guillaume Apollinaire foi um ardente defensor dos jovens artistas cubistas. Em seu célebre livro Méditations esthétiques, les peintres cubistes, publicado em 1913, ele escreveu:

[...] tem-se criticado vivamente nos pintores novos suas preocupações geométricas. Não obstante, as figuras geométricas são o essencial do desenho. A Geometria, ciência que tem por objeto o espaço, sua medida e suas relações, tem sido em todas as épocas a regra essencial da pintura. Até hoje, as três dimensões da Geometria Euclidiana foram suficientes para as inquietudes que o sentimento infinito desperta na alma dos grandes artistas. Os pintores novos, como seus antecessores, não se propuseram a ser geômetras. Mas pode-se dizer que a geometria é para as artes plásticas o que a gramática é para a arte do escritor. (APOLLINAIRE apud GULLAR, 1998, p. 77-78)

Outro artista que utilizou fortemente elementos geométricos em sua obra foi o holandês Piet Mondrian, cuja produção foi muito influenciada pelo Cubismo. Entretanto, suas ideias e seus caminhos vieram a se tornar mais radicais, deixando que as figuras fossem completamente substituídas por simples composições de formas geométricas e cores primárias, além do preto e branco. O holandês Maurits Cornelius Escher ${ }^{1}$ é referência obrigatória em trabalhos envolvendo Matemática e Arte. Suas obras expressam notável combinação de sensibilidade e precisão técnica, e a chave para os surpreendentes efeitos de suas gravuras é a Geometria. Em seus trabalhos, ele

\footnotetext{
${ }^{1}$ Para saber mais sobre Escher acesse http://www.mcescher.com/
} 
demonstrou um grande domínio dos princípios fundamentais dessa disciplina e uma poderosa intuição na compreensão das relações espaciais.

Uma constante na arte de M.C. Escher era o revestimento ou a pavimentação regular de uma superfície, com a utilização de padrões que se justapunham. Sua inspiração veio a partir de estudos profundos que realizou sobre a arte e a cultura árabes e suas propriedades geométricas. Estas estavam repletas de simetrias e padrões de repetição, mas limitavam-se a figuras de formas abstrato-geométricas. Escher não se limitou a essas formas e usou como elemento padrão figuras concretas, perceptíveis e existentes na natureza, tais como peixes, aves, répteis, etc. Escher também apreciava os cinco poliedros platônicos: o cubo ou hexaedro regular, o tetraedro regular, o octaedro regular, o dodecaedro regular e o icosaedro regular. Esses sólidos são figuras frequentes em suas obras. Durante sua vida, Escher leu ensaios e correspondeu-se com matemáticos e cristalógrafos. Ele dizia: "eu frequentemente sinto ter mais em comum com os matemáticos do que com os meus colegas artistas”. Em 1954, expôs seus trabalhos no Congresso Internacional de Matemática, em Amsterdã. A partir de então, passou a proferir conferências e a participar de exposições não só em centros de estudos, museus e salões de arte, como também em centros de matemática em diversos países.

Além destes, podemos citar muitos outros artistas de diferentes tendências da arte que utilizaram a Matemática na elaboração de suas obras como, por exemplo, Salvador Dalí, Waldemar Cordeiro, Luiz Sacilotto, Amílcar de Castro, Geraldo de Barros, Judith Lauand, e Antônio Peticov.

$\mathrm{Na}$ pesquisa nos inspiramos em Lygia Clark, artista mineira que revolucionou a arte brasileira e o espaço do museu, ao se deslocar da posição de artista inteiramente responsável pela criação de uma obra para a de propositora, rompendo com a ideia de que a arte devia ser apenas contemplada. Lygia Clark criou objetos de arte que estimulavam a participação ativa do público e sua interação com a obra. $\mathrm{O}$ espectador passa então da contemplação à ação. Em suas exposições ela colocava a placa "Por favor, toque nas obras."

Em 1960 cria a série "Bichos", que são objetos móveis constituídos por placas de metal que se unem por meio de dobradiças, possibilitando infinitas posições quando manipulados. $\mathrm{O}$ "Bicho" não se compõe de formas independentes. Suas partes jogam harmoniosamente umas contra as outras, como um verdadeiro organismo. A obra vai se transformando à medida que a movimentamos, num gesto contínuo de recriação da obra. Em 1964 cria "Caminhando", obra que expressa claramente essa intenção, ao propor que o ato de fazer a obra fosse a própria obra. Nela o participante cria uma fita de Mobius [August Ferdinand Möbius (1790-1868) matemático alemão], uma superfície que subverte o princípio euclidiano de uma superfície possuir dois lados. A mesma é uma superfície unilateral. 
Interação e participação são a tônica de todo o trabalho de Lygia Clark, e justamente são essas as palavras que acreditamos que devem estar presentes em toda sala de aula, e em especial na sala de aula de Matemática. O professor não pode mais ser apenas um transmissor de conhecimentos. Ele precisa ser um mediador entre o conhecimento e o aluno. Seu objetivo principal deve ser o de criar condições para que o aluno participe ativa e independentemente na construção do seu próprio conhecimento.

O trabalho com Matemática e Arte possibilita uma grande integração e significação na aprendizagem, propiciando uma efetiva participação dos alunos na sala de aula. Em todos os projetos que desenvolvemos, a História, a Geografia e a Língua Portuguesa foram disciplinas que se integraram de modo natural ao trabalho, possibilitando assim a criação, em nossas salas de aula, de um diálogo interdisciplinar permanente.

\section{Sacilotto e o Concretismo Brasileiro}

O surgimento do Movimento Concretista foi um acontecimento de extraordinária importância da vida cultural brasileira na década de 1950, tanto no campo das artes plásticas como na literatura e na música. No mundo este movimento teve como seu principal representante o suíço Max Bill (1908 1994), que defendia a ligação entre a Arte e a Matemática. Ele dizia que o elemento de toda obra plástica é a Geometria, relação de posições sobre o plano e no espaço. A adoção da Matemática por parte do artista, como método e fonte de inspiração, abriria novos caminhos à linguagem da arte. "Estou convencido de que é possível desenvolver uma nova forma de arte na qual o trabalho do artista poderia basear seu conteúdo num grau bastante substancial na linha de abordagem matemática" (BILL, 1954, p. 28 ).

Em 1951, Max Bill recebeu o prêmio internacional de escultura, na I Bienal de São Paulo, com a obra Unidade Tripartida (1948-1949). A partir daí suas ideias passaram a influir profundamente no curso da arte brasileira.

O artista plástico Luiz Sacilotto ${ }^{2}$ (1924 -2003) nasceu em Santo André, São Paulo, e, ao lado de nomes como Geraldo de Barros, Alexandre Wollner, Hermelindo Fiaminghi, Judith Lauand e Waldemar Cordeiro, foi responsável pela introdução do movimento concretista no Brasil. Considerado o mais concreto entre os artistas concretos, deixou um conjunto significativo de obras que envolviam desenhos, gravuras, esculturas e pinturas. Ele dizia que: "Depois da invenção da máquina fotográfica não faz mais sentido pintar figuras."

\footnotetext{
${ }^{2}$ Para maiores informações sobre Luiz Sacilotto acesse http://www.sacilotto.com.br
} 
Sua relação com a arte, a arquitetura e o universo industrial começou desde cedo. Trabalhou como desenhista de letras, como publicitário e desenhista de arquitetura. Suas primeiras obras datam de 1942. A partir de 1954 começa a dar às suas obras o título de Concreção e as numera pelo ano e sequência de execução.

Iniciamos o projeto Sacilotto e o Concretismo Brasileiro reunindo estudos sobre a vida e obra de Luiz Sacilotto, procurando caracterizar o momento histórico, político e social de sua época. Passamos então a pesquisar o Movimento Concretista Brasileiro, e artistas que integravam esse movimento, incluindo aqui poetas concretos como Décio Pignatari, Haroldo de Campos e Augusto de Campos. Depois pedimos aos alunos que elaborassem suas próprias poesias concretas. O poema concreto rompe com a estrutura discursiva do verso tradicional e utiliza, além dos recursos usuais da poesia (ritmo, rima, etc), o significado e a disposição das palavras na página para uma comunicação imediata, visual, direta e concreta com o leitor.

Em suas obras, Luiz Sacilotto brinca com as formas e cria ilusões, utilizando materiais como alumínio, latão, ferro, madeira e esmalte. Ele dizia que:

Quando folheei os primeiros livros de geometria, deparei-me com triângulos, retângulos, círculos. Aprendi que aquelas formas serviam para alguma coisa, mas também percebi que eram formas bonitas. Elas foram, cada vez mais, me cativando. Percebi com o tempo que o desenvolvimento dessas formas pode dar resultados surpreendentes, extraordinários. Eu acho que cada pessoa deve ter uma coisa fundamental em sua vida. A minha é lidar com essas formas. (Exposição Audácia Concreta: as colagens de Luiz Sacilotto - CAIXA Cultural São Paulo, 2012)

Propusemos aos alunos a construção, com material de desenho geométrico e com o software Régua e Compasso, da obra Concreção 6047.

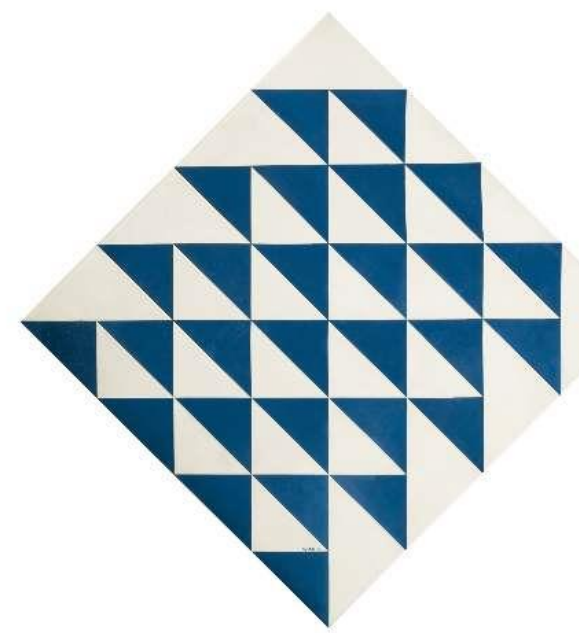

Fonte: Sacilotto, 1960 
A partir daí muitos conceitos foram trabalhados, dentre eles o estudo dos triângulos e outras figuras geométricas planas, congruência e semelhança de figuras, perímetro e área.

Sacilotto foi também pioneiro no âmbito da tridimensionalidade, ao desdobrar o plano no espaço. Suas esculturas foram construídas a partir de uma figura geométrica plana que, com cortes e dobras, se transformava em formas tridimensionais. Assim, em outra etapa do projeto, pedimos aos alunos que, em grupos, observassem a obra Concreção 5940, e que a construíssem com recortes e dobraduras de papel, registrando os conteúdos matemáticos que poderiam ser explorados durante a sua construção. A partir daí propusemos muitas outras atividades. Ao final pedimos que eles criassem a sua própria escultura utilizando a técnica empregada por Sacilotto.

Figura 2 - Concreção 5940

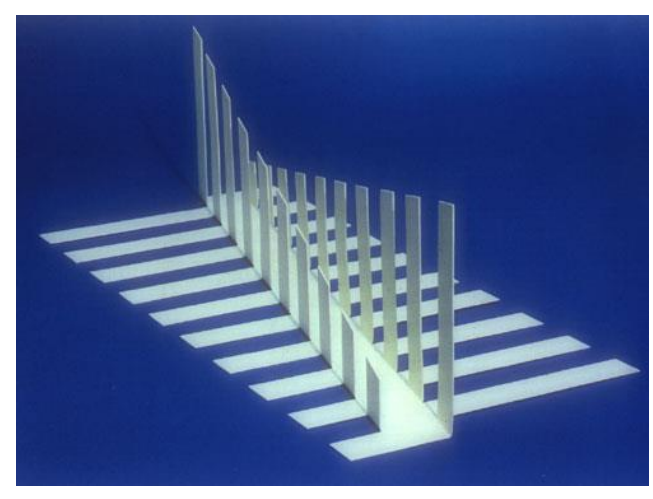

Fonte: Sacilotto, 1959

Sacilotto foi ainda um dos precursores da $O p$ Art no Brasil. Quem vê algumas de suas obras dessa fase tem a impressão de que elas se movimentam sozinhas, devido ao rigor matemático da composição que cria ilusões de óptica. Os alunos pesquisaram sobre o movimento $O p$ Art, seus artistas, em especial o pintor Victor Vasarely, e depois reproduziram algumas obras de Sacilotto e criaram, em grupo, as suas próprias obras Op Art.

Figura 3 - Concreção 9526

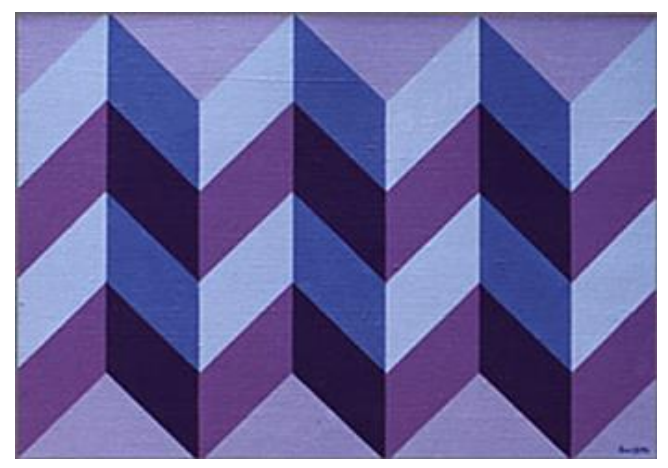

Fonte: Sacilotto, 1995 
Figura 4 - Reprodução de obras

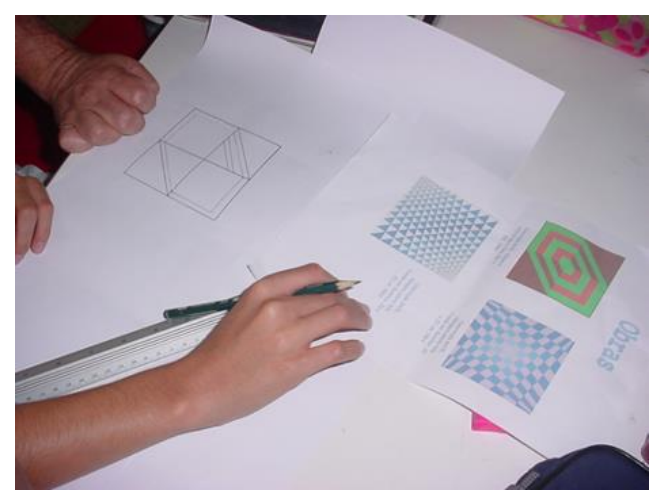

Fonte: Elaborada pela autora

Em seus últimos trabalhos, Luiz Sacilotto procurou nas colagens a técnica para vencer as limitações motoras impostas por um derrame sofrido em 1994. Dessa experiência surgiu uma série de colagens em preto e branco, recortadas em vinil adesivo, que exibem frações de círculos. Ele montava o quadro usando formas congruentes que eram colocadas em diferentes posições. $\mathrm{O}$ resultado é vertiginoso. Pedimos então aos alunos que criassem obras utilizando o mesmo método empregado por Sacilotto.

Figura 5 - Recorte 0022

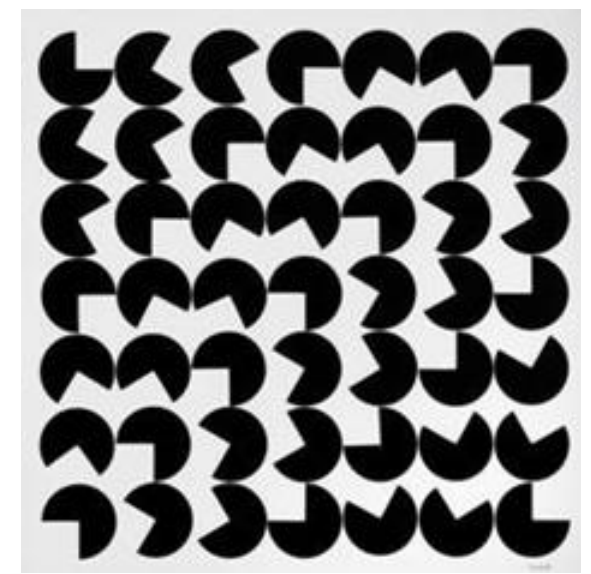

Fonte: Sacilotto, sem data

Muitos outros trabalhos fizeram parte do projeto com este grande artista brasileiro. A culminância do projeto Sacilotto e o Concretismo Brasileiro se deu com a montagem de uma exposição dos trabalhos realizados. Para conhecer um pouco mais sobre o nosso trabalho com Matemática e Arte acesse: www.matematicaearte.com.br. 


\section{Referências}

AMARAL, A. (org.). Arte Construtiva no Brasil - Coleção Adolpho Leirner. DBA Melhoramentos, 1998.

ÁVILA, G. Objetivos do Ensino da Matemática. Revista do Professor de Matemática. São Paulo, n. 27, p.1-10, 1995.

BARBOSA, A. M. A imagem no ensino da arte. 6 ed. São Paulo: Perspectiva, 2005.

BILL, M. The mathematical approach in contemporary art. Arts and Architecture. Los Angeles: 1954.

FAINGUELERNT, E. K. Educação matemática: representação e construção em geometria. Porto Alegre: Artmed, 1999.

et al. Trabalhando com geometria. São Paulo: Ática, 1989.

FAINGUELERNT, E. K.; NUNES, K. R. A. Fazendo arte com a matemática. Porto Alegre: Artmed, 2005.

.Tecendo matemática com arte. Porto Alegre: Artmed, 2009.

.Descobrindo matemática na arte. Porto Alegre: Artmed, 2010.

. Matemática: práticas pedagógicas para o ensino médio. Porto Alegre: Penso, 2012.

Fazendo arte com a matemática. 2 ed. Porto Alegre: Penso , 2015.

GULLAR, F. Etapas da arte contemporânea: do cubismo à arte neoconcreta. 2. ed. Rio de Janeiro: Revan, 1998.

KOLLER, M. C. M. C. Escher gravura e desenhos. Trad. Maria Odete Gonçalves. Taschen, 1994.

NUNES, K. R. A. Um olhar matemático no mundo das artes: a arte do século XX como veículo de aprendizagem em geometria. Dissertação de Mestrado-USU, Rio de Janeiro, 2002.

PARÂMETROS CURRICULARES NACIONAIS para o ensino fundamental ( $3^{\circ} \mathrm{e} 4^{\circ}$ ciclos) Matemática. Brasília: MEC/SEF, 1998.

PARÂMETROS CURRICULARES NACIONAIS para o ensino fundamental ( $3^{\circ} \mathrm{e} 4^{\circ}$ ciclos) Artes. Brasília: MEC/SEF, 1998.

SALVADOR, M. Uma História de Paixão: Estela Kaufman Fainguelernt e o Ensino da

Geometria. 2012. Dissertação de Mestrado (Educação Matemática). Vassouras (RJ): Universidade Severino Sombra.

ZIRALDO, A. P. Uma professora muito maluquinha. São Paulo: Melhoramentos, 1995.

WALKER,W. et al. Caleidociclos de M.C. Escher. Trad. Maria Odete Gonçalves. Taschen, 1991. 